This item was submitted to Loughborough's Research Repository by the author.

Items in Figshare are protected by copyright, with all rights reserved, unless otherwise indicated.

\title{
Conversions of surface grain-size samples collected and recorded using different procedures
}

PLEASE CITE THE PUBLISHED VERSION

http://dx.doi.org/10.1061/(ASCE)HY.1943-7900.0000595

PUBLISHER

C ASCE (American Society of Civil Engineers)

VERSION

AM (Accepted Manuscript)

LICENCE

CC BY-NC-ND 4.0

\section{REPOSITORY RECORD}

Graham, David J., Anne-Julia Rollet, Stephen P. Rice, and Herve Piegay. 2019. "Conversions of Surface Grain-size Samples Collected and Recorded Using Different Procedures". figshare.

https://hdl.handle.net/2134/9874. 
This item was submitted to Loughborough's Institutional Repository (https://dspace.lboro.ac.uk/) by the author and is made available under the following Creative Commons Licence conditions.

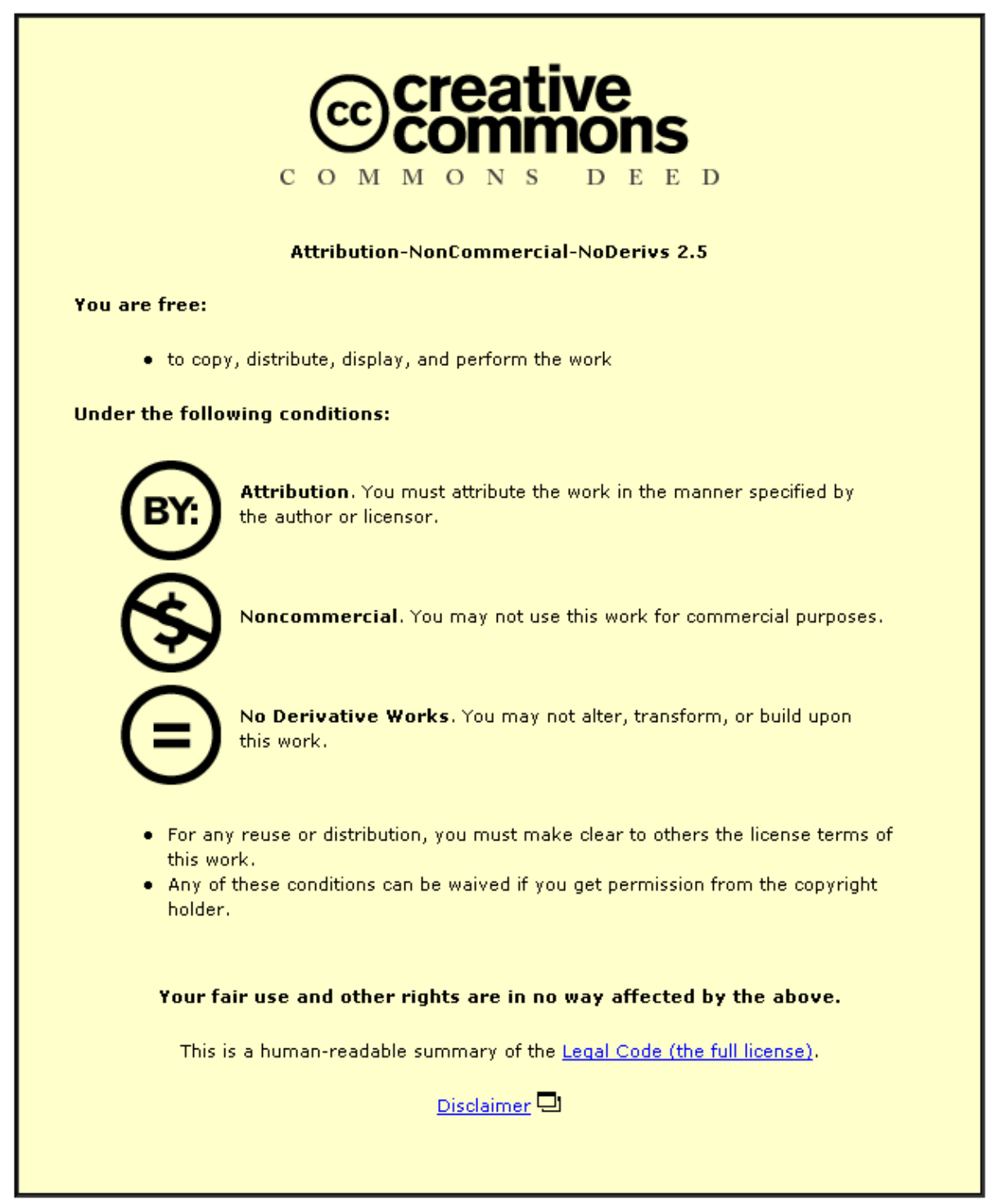

For the full text of this licence, please go to: http://creativecommons.org/licenses/by-nc-nd/2.5/ 
$\mathrm{HY} / 7097$

\title{
Conversions of Surface Grain-Size Samples Collected and Recorded Using Different Procedures
}

\author{
David J. Graham ${ }^{1}$; Anne-Julia Rollet ${ }^{2}$; Stephen P. Rice ${ }^{3}$; Hervé Piégay ${ }^{4}$
}

${ }^{1}$ Lecturer in Physical Geography, Polar and Alpine Research Centre, Department of Geography, Loughborough University, Loughborough, Leicestershire, LE11 3TU UK (corresponding author). E-mail: D.J.Graham@lboro.ac.uk

\begin{abstract}
${ }^{2}$ Assistant Professor, Université Caen Basse Normandie, Geophen - CNRS, UMR 6554 France.

${ }^{3}$ Reader in River Science, Centre for Hydrological and Ecosystem Science, Department of Geography, Loughborough University, Loughborough, Leicestershire, LE11 3TU UK.

${ }^{4}$ Research Director, National Center of Scientific Research - CNRS, University of Lyon, UMR 5600, Site ENS-lsh, Lyon, France.
\end{abstract}

\begin{abstract}
:
Information about the grain-size distribution of the surface layer of sediment exposed on river beds is often critical in studies of fluvial hydraulics, geomorphology and ecology. A variety of sampling and analysis techniques are in common usage which produce grain-size distributions that are not directly comparable. This paper seeks to explore the appropriate conversions between different types of surface grain-size sampling methods. This is particularly timely in the light of increasingly widespread use of automatic and semiautomatic image-based measurement methods, the comparability of which with conventional measurement methods is relatively poorly constrained. For conversions between area-bynumber (paint-and-pick) and grid-by-number (pebble count) samples, the empirically-derived conversion factor $( \pm 2.2)$ was found to be greater than that predicted by the Kellerhals and Bray model $( \pm 2)$, but the errors associated with using the value predicted by the model were small (3.8\% in $\mathrm{mm})$. For conversions between areal samples recorded by count and weight,
\end{abstract}


the empirically-derived conversion factor was approximately \pm 2.9 , but the use of the value predicted by the Kellerhals and Bray model $( \pm 3)$ resulted in only small errors $(5.2 \%$ in $\mathrm{mm})$. Similarly, for conversions between image-based grain-size distributions recorded in area-bynumber and grid-by number form, the emipirically-derived conversion factor was \pm 1.9 , but the using the model value of \pm 2 resulted in only small errors $(4.1 \%$ in $\mathrm{mm})$. Although these results are specific to the datasets analysed, the variety of sedimentary conditions included gives us confidence that the results are representative.

\section{Introduction}

The grain-size distribution of coarse-grained sediment exposed in the surface layer of a landform or deposit is often of particular importance. In river hydraulics, the interaction between the surface layer and the water flowing over it defines the skin resistance to flow and the character of the boundary layer. Surface grain-size distributions are therefore of importance for flow modeling in rivers (e.g. Nowell and Church 1979; Ferguson 2007) and are a key control on spatial and temporal variations in flow characteristics (e.g. Clifford 1996; Nikora and Walsh 2004; Lamarre and Roy 2005; Buffin-Bélanger et al. 2006). In fluvial geomorphology, this layer provides a primary reservoir of potentially mobile bedload that, in armored perennial channels, guards access to more substantial subsurface stores. The surface grain-size distribution is therefore a key parameter in the estimation of bedload transport (e.g. Parker 1990; Wilcock and Crowe 2003; Cui 2007). The grain sizes in the surface layer determine its texture, microtopography and porosity and thereby its propensity to filter mobile sediments, rejecting some grains and retaining others (e.g. Bluck 1982; Frostick et al. 1984). Surface grain-size distributions therefore influence vertical and areal sorting processes which are important for surface-subsurface sediment exchange, for armor development, for 
building bedforms and for generating patchiness (e.g. Andrews and Parker 1987; Paola and Seal 1995).

In a more general sense the surface layer generally provides the most accessible information about the granulometry of a bulk sediment and may be the only source of such information in cases where subsurface sampling is impracticable. For these reasons, amongst others, accurate characterization of surface grain-size distribution is necessary in many research and management applications in engineering, geomorphology, sedimentology, and ecology.

For coarse-grained sediments, such information is commonly obtained by collecting a fixed number of grains on a regular grid (Wolman 1954), or by collecting all of the grains within a fixed area (e.g. Lane and Carlson 1953, Diplas and Fripp 1992). The relative speed of gridbased sampling has resulted in its adoption as a de facto standard, despite well documented biases and limitations (e.g. Marcus et al. 1995, Wohl et al. 1996). However, recent developments in automated measurement techniques using digital images (Butler et al. 2001; Rollet et al. 2002; Sime and Ferguson 2003; Graham et al. 2005a,b; Rollet 2007), have led to an increase in the prevalence of areal sampling. Whilst it is possible to apply grid-based sampling to photographs, this is inefficient because most of the grains remain unmeasured and multiple photographs are likely to be required to obtain an adequate sample size.

The increasing popularity of image-based surface sampling methods, and the need to compare the resulting data with that from more traditional approaches (e.g. grid-based measures), means it is timely to revisit the nature of the appropriate conversions between them. This paper therefore provides new information to clarify these issues. First, the relations between area- and grid-based samples are assessed in the absence of operator and sampling biases using image-based methods. Second, the same relations are examined using conventional field methods (pebble counts and paint-and-pick sampling) to assess the effect 
of introducing operator and sampling biases. Finally, the relations between samples recorded based on particle counts and weights are assessed. These data will provide practitioners with information to make informed decisions about the nature of appropriate conversions between samples collected and recorded using different procedures without recourse to the comparatively complex methods of Shirazi et al. (2009).

\section{Theoretically- and empirically-derived conversions}

Areal sampling methods have a key advantage over grid-based methods: they capture grainsize information over small areas rather than integrating information across larger surfaces. This removes the risk of inadvertently merging data from two or more adjacent facies whilst facilitating the capture of information about small-scale variability in grain size. Image-based data capture has additional benefits. The time spent in the field is substantially reduced, lowering costs, and the surface is not damaged - a key consideration for many monitoring and ecological applications. Where automated processing is used to extract grain-size information from the images, analysis time in the laboratory is also minimal. These characteristics mean that image-based approaches have the potential to resolve important spatial and temporal variability that was either impossible or prohibitively expensive previously.

In addition to grid- and area-based sampling methods, data may be recorded based on either the weight or number of grains within individual size fractions. Grid sampling is most commonly combined with grain counts. Where field-based methods of areal sampling are used (e.g. paint-and-pick sampling, Lane and Carlson 1953), the large number of grains collected means that grading is most easily achieved by sieving and weighing on return to the laboratory. Photographic sampling methods must be combined with grain counts because the weight of grains is unknown (although Ibekken and Schleyer 1986 developed a method for 
estimating their weights based on measurements of their apparent axes and assumptions about their shape and density).

Kellerhals and Bray (1971) demonstrated that surface grain-size distributions derived by the four possible combinations of sampling and recording methods (grid-by-number; grid-byweight; area-by-number; area-by-weight) are not directly comparable. However, it is frequently necessary to convert data collected using one combination to make it equivalent to data collected using another. Appropriate conversions between data collected using different sampling techniques have been the subject of a considerable debate over four decades, much of which has focused on conversion between grid-by-number sampling of surface sediments and bulk sampling of the subsurface (Gomez 1983; Anastasi 1984; Ettema 1984; Diplas and Sutherland 1988; Rice and Haschenburger, 2004). Appropriate conversions between different types of surface sample have received comparatively little attention.

Theoretically, conversions between different surface sampling and recording techniques are straightforward for randomly distributed equant grains with uniform density when operator bias is disregarded (Table 1). These conversions - derived by Kellerhals and Bray 1971 and commonly referred to as the 'voidless-cube model' (Bunte and Abt 2001a) - are based on the assumption that particle area is proportional to the square of the grain size and particle weight is proportional to the cube of the grain size. So, to convert from a weight- to a number-basis, the proportion of the total sample weight of a particular size $D$ is multiplied by $D^{-3}$. Conversions are generally applied to data aggregated into size classes, in which case the value of $D$ used is the geometric centre-point of the class, but conversions may also be applied to individual grains where appropriate data are available. Deviations from these conversion factors might be expected for non-equant grains. Where there are substantial variations in grain density within the sample (e.g. for some combinations of volcanic rocks) 
this will affect the conversion factor for weight/number conversions, but such circumstances are likely to be rather unusual.

In response to evidence that the Kellerhals and Bray (1971) model does not accurately reproduce field comparisons between surface and subsurface samples, Diplas and Sutherland (1988) refined the model to incorporate voids, more accurately reflecting the fact that real sediment bodies have pore spaces. Fraccarollo and Marion (1995) presented a more general but consistent model based on the statistical properties of a homogenous mixture incorporating voids.

The presence of voids complicates conversions considerably by introducing the possibility that surface sampling techniques may either include grains that lie below surface voids (i.e. that are stratigraphically in a layer below the surface, but nevertheless exposed to the flow), or exclusively sample those grains that protrude into the flow. According to Diplas and Sutherland (1988, p. 491) for grid sampling, "one does not lift up a grain through the voids of the top layer if the grid point falls above [...] a void. Instead, the grain of the top layer closest to the grid point will be removed." The extent to which this is true is likely to depend on the precise sampling methodology followed and the size of the interstices. If a pointed finger is used to select a grain that lies in a small interstice, the probability of touching the particle at the side of the interstice is high, especially underwater (Fripp and Diplas 1993; Marcus et al. 1995). If a sharp pointer is used in combination with a sampling frame or tape (Bunte and Abt 2001b), and care is taken when extracting the grain it, this assumption is likely to be incorrect.

These differences are significant because the conversions predicted by the Kellerhals and Bray (1971) model only hold when particles beneath surface voids are excluded from the sample. That is, the conversion is only valid when an operator bias against small interstitial 
grains is introduced. Whilst there is some justification for believing that this may be true for grid samples, it is certainly not true for certain types of areal sample. Indeed, some areal samples may be subject to an opposite bias in favor of small interstitial particles. Adhesive sampling agents (e.g. wax, clay, resin and grease) penetrate voids to differing extents depending on the nature of the agent and the porosity of the sediment (Diplas and Sutherland 1988). This may result in the removal of substantial numbers of small grains both from within the interstices between larger grains and from the subsurface sediment layer. Paint-and-pick sampling (Lane and Carlson 1953) is designed to include all grains that are exposed to the flow, including those within interstices, but may also result in the inclusion of subsurface grains as a result of penetration and drifting by the paint, or overzealous collection of fine grains by the operator (Church et al. 1987). Photographic sampling techniques aim to sample all of those grains exposed to the flow but may miss those grains that lie deep within interstices as a result of shadows from, or substantial hiding by, other grains.

The appropriate conversion between two samples collected by different methods may be derived empirically (Proffitt 1980). This approach is used here to explore the appropriate conversions between surface samples obtained using a variety of methods and to compare these empirical results with the theoretical conversion factors in Table 1. The general form of the relation between grain-size samples collected by different methods from the same population is:

$p\left(\operatorname{proc}_{1}\right)_{i}=K \cdot p\left(\operatorname{proc}_{2}\right)_{i} \cdot D_{i c}^{x}$

where $p\left(\operatorname{proc}_{n}\right)_{i}$ is the percentage of the size fraction $i$ obtained from sampling procedure $n$, $D_{i c}$ is the geometric centre of the same size fraction, $K$ is a constant, and $x$ is the conversion

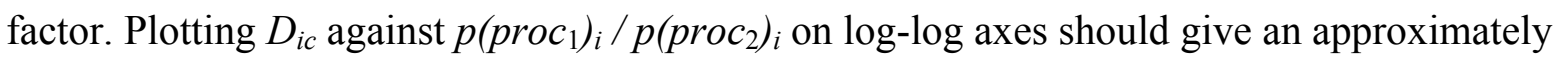
straight line (indicating that a power function describes the data), the gradient of which may 
be determined by regression and is equivalent to the conversion factor, $x$. Because neither proc $_{1}$ or proc $_{2}$ can be considered independent variables, model II regression should be used (in which the sum of the squares of the normal deviates is minimized; York 1966; Peltzer 2007). A disadvantage of this method for determining the conversion factor is that the width of the fractions (bins) used has an effect on the results obtained. Additionally, where the size of individual grains is obtained (e.g. when measured with a ruler or using image-processing based methods), some information is lost by dividing the data into size fractions. Because most workers use half-Psi sieves for grading sediment, all conversion factors derived here are based on half-Psi size fractions.

\section{Validation of grid/area conversions}

\section{Image-based assessment}

In the absence of operator bias, the probability of selecting a particular grain when using a grid-based sampling method is proportional to its exposed (planform) area. In an equivalent areal sample all particles have an equal probability of being selected (equal to 1). It follows that it is possible to convert between grid- and area-based samples by weighting each individual grain based on its actual exposed area to reflect the relative probabilities of selecting a particular grain using the two sampling approaches.

In practice, measurements of grain areas are rarely available and it is most usual to apply conversions of the type outlined in Table 1 (Kellerhals and Bray 1971; Diplas and Sutherland 1988). However, photographic techniques have the potential to measure both the size and actual exposed area of each grain. Sime and Ferguson (2003) used this information to derive grid-by-number data from a photographic sample by attributing each grain to a half-Psi size class and then summing the total area in each class. These areas then represent the grid-by- 
number size distribution and percentiles may be derived by interpolation in the same way as for sieve-derived data. An alternative method, that takes full advantage of the ability of image-based methods to measure every grain, is to weight each grain individually by its size.

The algorithm used is a follows:

1. Measure the apparent $b$-axis and exposed area of every grain in the image. Place them in columns 1 and 2 . In this study, the $b$-axis of each grain was defined as the minoraxis of the best-fit ellipse and its area as the number of pixels within the grain and multiplied by the area represented by each pixel.

2. Sort the data by column 1 ( $b$-axis).

3. Calculate the percentage of the total area represented by each grain (column 2) and place in column 3 .

4. Calculate the cumulative sum of column 3 and place in column 4 .

5. Columns 1 and 4 can now be used to read off grain-size percentiles in grid-by-number equivalent form. For example, find the value $50 \%$ in column 4 and the median grain size will be indicated in the same row in column 1.

$A$ MATLAB ${ }^{\circledR}$ function to automate the method is available via the Loughborough University Physical Geography Resources Gateway (http://www.lboro.ac.uk/research/phys-geog/).

Although photographic sampling is unlikely to be entirely free of bias, by measuring both the size and area of individual grains, photographic methods enable the direct determination of the size distribution in both area- and grid-by number form using the same grains. This means that the theoretical conversions presented in Table 1 can be evaluated on a single dataset 
without the complications of bias introduced by comparing between different sampling methods that are measuring different grains.

This approach was applied to a dataset consisting of 37 photographic samples collected from three British gravel-bed rivers (Ettrick Water, n=15; Afon Ystwyth, $n=15$; River Lune, $n=7$ ), representing a wide variety of textures and clast characteristics (Table 2). All of the photographs were processed using the Sedimetrics ${ }^{\circledR}$ Digital Gravelometer software (http://sedimetrics.com/), based on the methods developed by Graham et al. (2005a, b) to determine the $b$-axis size and exposed area of all grains with an apparent $b$-axis larger than 8 $\mathrm{mm}$.

The empirical approach of Proffitt (1980), described above, was used to determine the appropriate conversion factor for each river (Table 3). The mean $r^{2}$ value for the least-squares regression models is 0.99 , indicating that the quality of the models is very high. For the three sites taken as a whole, the mean conversion factor is 1.83 , although there is some variability between sites. The aggregate results of the analysis for each of the 37 pairs of samples are presented in Figure 1. Figure 1b shows the conversion factor for each of the sample pairs, along with their $95 \%$ confidence limits.

Despite the high $\mathrm{r}^{2}$ values associated with the regression models, it is clear that there is significant deviation from a power relation in the largest size class for some of the samples and an associated tendency to reduce the gradient of the regression line (Figure 1a). Although this class contains a substantial proportion of the total area of the grains in each sample, it contains a very small number of grains, making it more likely to be influenced by individual, unusual particles. To overcome this effect, and generate a more robust estimate of the true conversion factor, the regression parameters were recalculated after excluding the largest size 
fraction. As would be expected, the result is a further increase in the mean $r^{2}$ value (to 0.999) and an increase in the mean conversion factor to 1.88 (Table 3, Figure 1c).

Although the robust estimate of the conversion factor is close to the theoretically-derived value of 2 (Table 1), the estimates are significantly different from the theoretical value at the 95\% confidence level in all except three cases (all of which are for the Ettrick Water data). These results cannot be attributed to differences associated with biases in individual sampling methods or random variations associated with different samples of the same population, because the data are for the same grains measured with the same image-based procedure. Therefore, it seems - for these sites at least - that in the absence of biases introduced by different sampling methods and sampling different grains, the theoretically-derived conversion factor slightly overestimates the true value.

A question that follows naturally from this analysis is: how much error is likely to be introduced if the theoretically-derived conversion factor of 2 is used rather than the empirically-derived factor? Figure 2 presents covariant plots of the $\Psi_{50}$ and $\Psi_{90}$ (Psi units, $\Psi$ $=\log _{2} D$, where $D$ is the particle size in $\mathrm{mm}$ ) derived directly in grid-by-number form and derived by conversion from area-by-number form using both the empirically derived, and theoretical, conversion factors. For the empirical case the average value of 1.88 was used for all sites. For consistency with the directly-derived grid-by-number percentiles, the conversion is applied to each individual grain and percentiles derived directly (rather than using the more conventional approach of aggregating the areas of grains within size classes and calculating percentiles by interpolation).

Errors are described following Sime and Ferguson (2003). Mean error, or procedure bias, $b$, is defined as $b=\frac{1}{n} \sum\left(\Psi_{m 1}-\Psi_{m 2}\right)$ where $n$ is the sample size (number of images multiplied 
by the number of percentiles used), $\Psi_{m 1}$ is a percentile derived from the first method and $\Psi_{m 2}$ is the equivalent percentile derived by the second method. The mean square error, $E_{m s}$, is defined as $E_{m s}=\frac{1}{n} \sum\left(\Psi_{m 1}-\Psi_{m 2}\right)^{2}$ and the irreducible random error, $e$, an indication of scatter, as $e=\sqrt{E_{m s}-b^{2}}$. Absolute errors in Psi units, $\varepsilon \Psi a b s$ may be converted into percentage errors in mm by $\varepsilon_{m m \%}=100\left(2^{\varepsilon_{\text {Yabs }}}-1\right)$.

Using the empirically-derived conversion factor results in an overall bias of 0.012 Psi $(0.8 \%$ in $\mathrm{mm}$ ) (Figure 2a; Table 4). The theoretically-derived conversion exponent results in an overall bias of -0.058 Psi ( $4.1 \%$ in $\mathrm{mm}$ ) (Figure $2 \mathrm{~b}$; Table 4$)$. The irreducible random error is similar for both cases. The differences between the sites are small.

\section{Field-based assessment}

The image-based assessment outlined above is useful because it directly compares grid- and areal-sampling approaches whilst excluding the effects of operator bias and errors associated with sampling different grains from the population. However, it is also appropriate to examine the appropriate conversion factors when these effects are present. Understanding the nature of appropriate conversions between areal and grid samples collected using conventional field methods is important because hybrid approaches are sometimes used to adequately capture the full grain-size distribution (Diplas and Fripp, 1992; Fripp and Diplas, 1993). Furthermore, the calibration and evaluation of image-based measurement techniques is often based on field-collected areal samples (e.g. Sime and Ferguson 2003; Graham et al. 2005b), whereas the results of image-based methods are generally presented in grid-based form to make them directly comparable with data from grid-based field sampling methods.

Datasets were collected on the Ain River, France and Fraser River, Canada (Table 2), to permit an assessment of the appropriate conversion between grid- and area-based samples. 
Grid-by-number (pebble count) samples were collected on a grid with node spacing approximately 2-times the maximum grain diameter and marked out with tapes across an area that the operator visually assessed to be texturally homogeneous. Area-by-number samples were collected from the centre of each of the grid-sampled areas using the paint-and-pick method (Lane and Carlson 1953; Church et al. 1987). Ten pairs of samples were collected on the Ain River, with the grid-by-number samples containing between 174 and 248 grains $($ mean $=210)$ and the area-by-number samples (collected over an area of $\left.0.6 \mathrm{~m}^{2}\right)$ yielding between 863 and 1796 grains (mean =1138). Eight pairs of samples were collected on the Fraser River, with the grid-by-number samples containing between 302 and 364 grains (mean $=344$ ) and the area-by-number samples (collected over an area of $0.25 \mathrm{~m}^{2}$ ) yielding between 297 and 763 grains (with a mean of 486). For both techniques, grains were graded using square-hole sieves or templates at half-Psi intervals and the number of grains in each class counted. All samples were truncated at 3 Psi $(8 \mathrm{~mm})$. When calculated in grid-by-number form, the $\Psi_{50}$ of the samples from the Ain River ranged from 3.8 Psi to 6.7 Psi and sorting from moderately well sorted to poorly sorted (inclusive graphic standard deviation between 0.6 Psi and 1.3 Psi). For the Fraser River, the $\Psi_{50}$ ranged from 4.7 to 5.5 Psi and samples were moderately or moderately well sorted (inclusive graphic standard deviation between 0.6 and 0.9 Psi).

Conversion factors for the conversion from area- to grid-based data were calculated (Figure 3; Table 5). Although the mean $r^{2}$ of the regression models is lower than for the image-based assessment, it is still very good at 0.94 for the Ain River and 0.81 for the Fraser River (Table 5). As for the image-based assessment, there is a deviation from a power relation in the coarsest size classes. This is especially marked for the Fraser River samples, presumably because the comparatively small areas of the paint-and-pick samples did not adequately characterize the coarsest part of the size distribution. To generate a more robust estimate of 
the correction coefficient, the regression parameters were recalculated excluding the largest size fraction. Following this procedure the mean $r^{2}$ of the regression models was increased to 0.95 for both sites (Table 5). The mean conversion factor is 2.21 with a standard deviation of 0.38 (Table 5). Ten of the eighteen regression lines have a gradient which is significantly different from the theoretically derived value of 2.0 at the $95 \%$ level (Figure 3c). Although less clear-cut than for the image-based assessment, it seems that the theoretically-derived conversion factor slightly underestimates the true value.

The error bars around the estimated conversion factors are substantially larger than for the image-based assessment, probably because - unlike for the image-based assessment - the two sampling approaches measured a different set of grains. The errors are likely to represent a combination of real differences in the populations sampled (because the pebble counts were collected over a larger area than the paint-and-pick samples), the random variations associated with making repeat samples from a single population, and the differing biases associated with the two sampling methods. It should be cautioned that these results are for a relatively small number of samples from two rivers so that the general applicability of the theoretically-derived conversion factor to other rivers with differing texture, sorting, and structure remains to be ascertained.

Figure 4 illustrates the effect of applying the theoretically-derived conversion on the precision of estimates of key percentiles. As before, errors are described with reference to the procedure bias, $b$, mean-square error, $E_{m s}$, and irreducible random error, $e$ (Table 6). Results for the Fraser River are not presented because the small paint-and-pick sample areas, and consequent underestimation of higher grain-size percentiles, make error comparisons on this basis inappropriate. 
Several key factors are apparent for the Ain River. As might be expected, the irreducible random error (represented by the scatter in Figure 4) is substantially larger than for the image-based analysis for the reasons already outlined. Nevertheless, the bias associated with a conversion from an areal (paint-and-pick) sample to make it equivalent to a grid (pebblecount) sample is small at only $-0.054 \mathrm{Psi}(3.8 \%$ in $\mathrm{mm})$ (Figure $4 \mathrm{a})$, supporting the assertion that this conversion is appropriate. Notably however, the results for the reverse conversion, to make a grid (pebble-count) sample equivalent to an areal (paint-and-pick) sample, are less good. Although the irreducible random error is similar, the bias is much larger at -0.198 $(14.7 \%$ in $\mathrm{mm})$ (Figure $4 \mathrm{~b})$. There is also a clear trend for the error to increase in coarser samples. It is likely that these effects result from the sensitivity of the conversion to small variations in the coarsest part of the grain-size distribution. This effect was examined in detail by Graham et al. (2005c).

\section{Validation of number/weight conversions}

Whereas volumetric subsurface samples are invariably recorded by the weight of grains within size classes, surface samples may be recorded in terms of either the number of grains or their weight. Based on the Kellerhals and Bray (1971) model, a conversion factor of 3 is generally used to transform between data recorded using different methods (Table 1). However, little data have been published to assess the appropriateness of this conversion, which is based on the assumption of equant grains. Using samples that have been graded and then both weighed and counted, the empirical method described above may be used to validate the conversion.

A total of 50 area-based samples were collected using the paint-and-pick method from the three British rivers referred to previously (Table 2). Twenty-one samples were collected from Ettrick Water, 18 from the Afon Ystwyth and 11 from the River Lune. All of the samples 
were returned to the laboratory and graded at half-Psi intervals using square-hole sieves and templates. Both the number and weight of clasts in each size class were recorded. All samples were truncated at $4 \mathrm{~mm}$. Samples contained between 917 and 6787 grains (mean $=2510)$.

Figure 5 illustrates the empirical determination of the conversion factor for transforming between weight and count data. The almost linear relations in Figure 5a indicate that a power function is a good description of the relation between the count and weight data. There is a slight tendency to deviate from linearity at the coarse end, presumably as a result of the influence of a very small number of (relatively large) grains, but this is insufficient to justify truncation of the coarsest fraction. For the three sites taken together, the mean $r^{2}$ of a linear fit is 0.999 and the mean conversion factor is 2.90 (Table 7). The conversion factor is less than 3 for all except one of the samples and the regression lines of 40 (out of 50) of the samples have gradients that are significantly different from 3 at the $95 \%$ level (Figure $5 \mathrm{~b}$ ), indicating that the theoretical value is likely to be an overestimate for real sediments. Perhaps unsurprisingly, the square blocky sediments of Ettrick Water have a mean conversion factor closest to the value of 3 predicted by the Kellerhals and Bray (1971) model. Nevertheless, the mean conversion factor for each of the three sites is similar, despite substantial differences in the physical properties of the sediment, suggesting that the appropriate conversion factor is rather insensitive to particle shape.

As before, it is reasonable to ask how much error is associated with the use of the theoretical conversion factor rather than the empirically-derived factor. Averaged across the three sites, for conversion from weight to number basis, the theoretical conversion factor of -3 results in a bias of 0.077 Psi (5.5\% in $\mathrm{mm})$ compared to a bias of $-0.007 \mathrm{Psi}(0.5 \%$ in $\mathrm{mm})$ if the empirically-derived factor is used (Table 8, Figure 6). For conversion from number to weight 
basis, the theoretical conversion factor of 3 results in a bias of -0.076 Psi ( $5.4 \%$ in $\mathrm{mm})$ compared to a bias of -0.032 Psi $(2.2 \%$ in $\mathrm{mm})$ for the empirically-derived factor.

\section{Discussion \& Conclusions}

The evidence presented in this paper is designed to inform the decisions made by practitioners whenever surface grain-size distributions sampled and recorded using different procedures are compared.

Such comparisons are challenging because different sampling procedures measure different sets of grains across different areas and are subject to different biases. Furthermore, all samples are subject to random sampling error. These factors mean that simple theoretical conversions of the type outlined in Table 1 are unlikely to be universally applicable, and their

use must be carefully justified. Such issues must be considered whenever data collected using different methods are compared but are particularly pertinent given the increasing use of image-based grain-sizing procedures, and the discussion below focuses on this context.

Practitioners will often wish to validate the results of image-based procedures at new field sites. Although the grain-size distribution is most likely to be required ultimately in grid-bynumber form (so it is comparable to pebble-count data), validation has most commonly been achieved using paint-and-pick sampling because both procedures are then sampling the same set of grains (e.g. Sime and Ferguson 2003; Graham et al. 2005b). The use of grid-based sampling for validation purposes is less appropriate because these would need to be applied over larger areas, would sample a different set of grains, and would introduce additional external errors. Nevertheless, a further complication is that whereas image-based procedures can only record the number of grains present, paint-and-pick samples used for validation are 
most easily recorded by weight after grading using sieves because of the large numbers involved.

These considerations mean that to use image-based grain-size measurement procedures practitioners need to be confident of four key issues:

(i) The image-based procedure must adequately identify the grains in the paint-and-pick control sample. This step is the validation of the image-based procedure itself and has been the focus of much of the published work on image-based methods (e.g. Sime and Ferguson 2003; Graham et al. 2005a).

(ii) The relation between the surface grain-size distribution as derived by paint-and-pick (area-by-number) sampling and pebble count (grid-by-number sampling) must be known. This is necessary because the paint-and pick-sample is the control for the image-based method, but the ultimate result is likely to be required in grid-by-number form to make it compatible with pebble-count data (the de facto standard for surface grain-size sampling). If there is a systematic bias between these two sample types then it must be corrected for.

The empirical analysis presented in Table 5 and Figure 3 indicates that in about half of cases the appropriate conversion factor is significantly different from the value predicted by the Kellerhals and Bray (1971) model. Nevertheless, if the theoretical value is used at our experimental site, the bias for conversions from areal to grid samples is very small $(-0.054$ Psi; $3.8 \%$ in $\mathrm{mm})$. The irreducible random error is comparatively large (0.298 Psi; $22.9 \%$ in $\mathrm{mm})$, but this is most likely attributable to random sampling errors. This result is interesting because when a more realistic model incorporating voids is used, a conversion factor of 2 should only be achieved when grains located beneath voids are excluded from the samples (Diplas and Sutherland 1988). This is very unlikely to have been the case for our paint-andpick samples, which are more likely to be biased in favour of fine grains located within the 
voids between larger particles. We also took great care to avoid such a bias when undertaking pebble counts. This result suggests that the errors associated with using the predictions of the Kellerhals and Bray (1971) model for converting between field-collected surface samples are likely to be small relative to random sampling errors.

(iii) If the paint-and-pick sample grain-size distribution was recorded by weight, the relation between weight and count data must be known. At our three experimental sites, the appropriate conversion factor is slightly lower than, and significantly different from, that predicted by the Kellerhals and Bray (1971) model. There is no significant difference between the three sites, despite their different grain-shape characteristics. Across all of the sites, a conversion factor of -2.90 appears most appropriate, resulting in an average bias of 0.007 Psi $(-0.5 \%$ in $\mathrm{mm})$. However, the use of the conversion factor of -3 predicted by the Kellerhals and Bray (1971) model results in only a small bias, averaging 0.077 Psi $(5.2 \%$ in $\mathrm{mm})$. Where possible, it is best to count the number of grains so that conversion is not required. However, if this is not practical, the use of conversions is likely to result in rather small errors.

(iv) The relation between the image-based grain-size distribution in area-by-number and gridby-number form must be known. This is important because the control data used to validate image-based procedures are most likely to be in area-by-number form. Whilst it is possible to record the results of image-based measurements directly in grid-by-number form, it may still be desirable to adjust the results of the image analysis so that the relation between imagederived grid- and area-based data is identical to that from field-derived grid- and area-based data.

For our three experimental sites, the empirical analysis presented in Table 4 indicates that the relation between image-based area- and grid-based samples is best explained by a conversion 
factor of 1.88 , resulting in an average bias of $0.012 \mathrm{Psi}(0.8 \%$ in $\mathrm{mm})$. Whilst this is significantly different from the conversion factor of 2 predicted by the Kellerhals and Bray (1971) model, the use of this value results in a rather small average bias of -0.058 Psi $(4.1 \%$ in $\mathrm{mm}$ ). On this basis, and particularly given the rather large irreducible random error associated with the relation between area- and grid-derived field data, there is little apparent justification for adjusting the grid-by-number image-derived data.

Overall, our results indicate that use of the Kellerhals and Bray (1971) conversions result in rather small errors. Consequently, practitioners are unlikely to find more complex frequency base methods (e.g. Shirazi et al. 2009) necessary for routine applications.

\section{Software}

Image-based measurements were made using the Sedimetrics ${ }^{\circledR}$ Digital Gravelometer software (http://sedimetrics.com/). All other analyses were undertaken using MATLAB ${ }^{\circledR}$ (http://mathworks.com/). Various scripts for undertaking analyses on grain-size data are available on the Loughborough University Physical Geography Resources Gateway (http://www.lboro.ac.uk/research/phys-geog/).

\section{Acknowledgements}

The collaborative work on which this paper is based was facilitated by a travel grant to DJG from Loughborough University. Fieldwork was funded by grants from The Leverhulme Trust, Loughborough University, Université de Lyon. Technical assistance was provided by Mark Szegner, Barry Kenny, Simon Dufour, and various graduate students at the University of British Columbia. The paper has been significantly clarified as a result of comments from the editor and 2 anonymous referees. 


\section{References}

Anastasi, G. (1984). “Geschiebeanalysen im felde unter berucksichtigung von grobkomponenten [Field grain-size analysis with special attention to coarse material].” Mitteilungen der Versuchsanstalt fur Wasserbau, Hydrologie und Glaziologie, 70, ETH Zürich.

Andrews, E. D., and Parker, G. (1987). "Formation of a coarse surface layer as a response to gravel mobility." Sediment Transport in Gravel-bed Rivers, C. R. Thorne et al., eds., pp. 269-323, John Wiley and Sons, Chichester.

Bluck, B. J. (1982). "Texture of gravel bars in braided streams." Gravel Bed Rivers: Fluvial Processes, Engineering and Management, R. D. Hey et al., eds., pp. 339-355, John Wiley \& Sons, Chichester.

Buffin-Bélanger, T., Rice, S., Reid, I., and Lancaster, J. (2006). "Spatial heterogeneity of near-bed hydraulics above a patch of river gravel." Water Resour. Res., 42, W04413, doi:10.1029/2005WR004070.

Bunte, K., and Abt, S. R. (2001a). "Sampling surface and subsurface particle-size distributions in wadable gravel-and cobble-bed streams for analyses in sediment transport, hydraulics, and streambed monitoring." Gen. Tech. Rep. RMRS-GTR-74, 428 pp., U.S. Department of Agriculture, Forest Service, Rocky Mountain Research Station, Fort Collins, CO.

Bunte, K., and Abt, S. R. (2001b). "Sampling frame for improving pebble count accuracy in coarse gravel-bed streams.” J. Am. Water Resour. Assoc., 37, 1001-1014. 
Butler, J. B., Lane, S. N., and Chandler, J. H. (2001). "Automatic extraction of grain-size data from gravel surfaces using digital image processing.” J. Hydraul. Res., 39, 519-529.

Church, M. A., McLean, D. G., and Wolcott, J. F. (1987). "River bed gravels: Sampling and analysis." Sediment Transport in Gravel-bed Rivers, C. R. Thorne et al., eds., pp. 43-79, John Wiley, Hoboken, N. J.

Clifford, N. J. (1996). "Morphology and stage-dependent flow structure in a gravel-bedded river." Coherent flow structures, P.J. Ashworth et al., eds., pp. 545-566, John Wiley and Sons, Chichester.

Cui, Y. (2007). "The unified gravel-sand (TUGS) model: simulating sediment transport in gravel/sand grain size distributions in gravel-bedded rivers." Water Resour. Res., 43, W10436, doi:10.1029/2006WR005330.

Diplas, P., and Fripp, J. B. (1992). "Properties of various sediment sampling procedures.” J. Hydraul. Eng., 118, 955-970.

Diplas, P. and Sutherland, A.J. (1988). "Sampling techniques for gravel sized sediments." Journal of the Hydraulics Division, Amer. Soc. Civil Eng. 114, 484-499.

Ettema R. (1984). “Sampling armor-layer sediments.” J. Hydraul. Eng., 110, 992-996.

Ferguson, R. (2007). "Flow resistance equations for gravel- and boulder-bed streams.” Water Resour. Res., 43, W05427, doi:10.1029/2006WR005422.

Fraccarollo, L., and Marion, A. (1995). "Statistical approach to bed-material surface sampling.” J. Hydraul. Eng., 121, 540-545. 
Fripp, J. B., and Diplas, P. (1993). "Surface sampling in gravel streams.” J. Hydraul. Eng., $119,473-490$.

Frostick, L. E., Lucas, P. M., and Reid, I. (1984). "The infiltration of fine matrices into coarse-grained alluvial sediments and its implications for stratigraphical interpretation." Journal of the Geological Society, 141, 955-965.

Gomez, B. (1983). "Representative sampling of sandy fluvial gravels.” Sedimentary Geology, 34, 301-306

Graham, D. J., Reid, I., and Rice, S. P. (2005a). “Automated sizing of coarse-grained sediments: Image-processing procedures." Mathematical Geology, 37, 1-28.

Graham, D. J., Rice, S. P., and Reid, I. (2005b). “A transferable method for the automated grain sizing of river gravels.” Water Resour. Res., 41, W07020, doi: 10.1029/2004WR003868.

Graham, D. J., Rice, S. P., and Reid, I. (2005c). “Comment: Photographic techniques for characterizing streambed particle sizes." Transactions of the American Fisheries Society, $134,1599-1603$.

Graham, D. J. Rollet, A.-J., Piégay, H., and Rice, S. P. (2010). "Maximizing the accuracy of image-based surface sediment sampling techniques: key issues." Water Resour. Res., 46, W02508, doi:10.1029/2008WR006940.

Ibbeken, H., and Schleyer, R. (1986). "Photo-sieving: A method for grain-size analysis of coarse-grained, unconsolidated bedding surfaces." Earth Surf. Processes Landforms, 23, $481-492$. 
Kellerhals, R., and Bray, D. I. (1971). "Sampling procedures for coarse fluvial sediments.” J. Hydraul. Div. Am. Soc. Civ, Eng., 97, 1165-1180.

Lamarre, H., and Roy, A. G. (2005). "Reach scale variability of turbulent flow characteristics in a gravel-bed river." Geomorphology, 68, 95-113.

Lane, E. W., and Carlson, E. J. (1953). "Some factors affecting the stability of canals constructed in coarse granular material." Proceedings of the 5th IAHR Congress, pp 37-48, Int. Assoc. of Hydraul. Res., Madrid.

Marcus, W. A., Ladd, S. C., Stoughton, J. A., and Stock, J. W. (1995). "Pebble counts and the role of user-dependent bias in documenting sediment size distributions." Water Resour. Res., 31, 2625-2631.

Nikora, V., and Walsh, J. (2004). "Water-worked gravel surfaces: high-order structure functions at the particle scale." Water Resour. Res., 40, W12601, doi:10.1029/2004WR003346.

Nowell, A. R. M., and Church, M. (1979). "Turbulent-flow in a depth-limited boundary layer." J. Geophys. Res. Oceans and Atmospheres, 84, 4816-4824.

Paola, C., and Seal, R. (1995). "Grain-size patchiness as a cause of selective deposition and downstream fining." Water Resour. Res., 31, 1395-1407.

Parker, G. (1990). "Surface-based bedload transport relation for gravel rivers.” J. Hydraulic Res., 28, 417-436.

Peltzer, E.T. (2007). "M-file to calculate a "MODEL-II" least squares fit.” Model I and Model II Regressions, <http://www.mbari.org/staff/etp3/regress/lsqfitma.m> (Aug. 20, 2010). 
Proffitt, G. T. (1980). "Selective transport and armoring of non-uniform alluvial sediments." PhD thesis, Univ. of Canterbury at Christchurch, Christchurch, New Zealand.

Rice, S., and Church, M. (1996). "Sampling surficial fluvial gravels: The precision of size distribution percentile estimates." J. Sediment. Res., 66, 654-665.

Rice, S.P. and Haschenburger, J.K. (2004). “A hybrid method for size-characterisation of coarse subsurface fluvial sediments", Earth Surface Processes \& Landforms, 29, 373-389.

Rollet, A. J. (2007). "Etude et gestion de la dynamique sédimentaire d'un tronçon fluvial à l'aval d'un barrage: le cas de la basse vallée de l'Ain." Thèse de doctorat de géographie, 305 pp., Université de Lyon, Lyon.

Rollet, A. J., Kauffmann, B., Piégay, H., and Lacaze, B. (2002). “Automated calculation of grain size percentiles using image analysis: example of the bars of the Ain River (France).” Paper presented at the River Bed Patches: Hydraulics, Ecology and Geomorphology, The British Hydrological Society, Loughborough, UK, 8 May 2002.

Shirazi, M. A., Faustini, J. M., and Kaufmann, P. R. (2009). "Streambed gravel sampling and frequency base conversion: A solution to data set sharing." Water Resour. Res., 45, W01414, doi:10.1029/2007WR006151.

Sime, L. C., and Ferguson, R. I. (2003). "Information on grains sizes in gravel-bed rivers by automated image analysis.” J. Sediment. Res., 73, 630-636.

Wohl, E. E., Antony, D. J., Masden, S. W., and Thompson, D. M. (1996). “A comparison of surface sampling methods for coarse fluvial sediments." Water Resour. Res., 32, 32193226. 
Wilcock, P. R., and Crowe, J. C. (2003). "Surface-based transport model for mixed-size sediment." J. Hydraulic Eng. ASCE, 129, 120-128.

Wolman, M. G. (1954). “A method of sampling coarse river-bed material”. Trans. $A G U, 35$, 951-956.

York, D. (1966). “Least-squares fitting of a straight line.” Canad. J. Phys., 44, 1079-1086. 
Table 1. Theoretical conversions between different sampling techniques according to Kellerhals and Bray (1971). Modified from Bunte and Abt (2001a).

Conversion from $\rightarrow$ to $\quad$ Conversion factor, $D^{x}$

Surface sampling method
Area $\rightarrow$ grid
$x=2$
Grid $\rightarrow$ area
$x=-2$

Recording method
Weight $\rightarrow$ number
$x=-3$
Number $\rightarrow$ weight
$x=3$ 
Table 2. Principal characteristics of the five sites for which data are presented in this paper.

Site Clast form $\quad$ Clast lithology

Ettrick Water, Scotland Generally subangular or Mainly gritstone and shale subrounded and equant
Afon Ystwyth, Wales
Generally platy
Fine-grained gritstone

River Lune, Englan

Generally rounded and

Mainly limestone with some

equant

sandstone

Ain River, France

Generally well rounded

Mainly limestone with some

and equant

granite and quartzite

Fraser River, Canada Generally well rounded Very mixed

and equant 
Table 3. Regression model parameters for image-based area-to-grid conversions.

\begin{tabular}{|c|c|c|c|c|c|c|c|c|}
\hline \multirow[t]{3}{*}{ Dataset } & \multicolumn{4}{|c|}{ All data ${ }^{(1)}$} & \multicolumn{4}{|c|}{$\begin{array}{l}\text { Excluding largest size } \\
\text { fraction }^{(2)}\end{array}$} \\
\hline & \multicolumn{2}{|c|}{$\mathrm{r}^{2}$} & \multicolumn{2}{|c|}{$\begin{array}{l}\text { Conversion } \\
\text { factor, } x^{(3)}\end{array}$} & $\mathrm{r}$ & & \multicolumn{2}{|c|}{$\begin{array}{l}\text { Conversion } \\
\text { factor, } x^{(3)}\end{array}$} \\
\hline & Mean & $\begin{array}{l}\text { St. } \\
\text { dev. }\end{array}$ & Mean & $\begin{array}{l}\text { St. } \\
\text { dev. }\end{array}$ & Mean & $\begin{array}{l}\text { St. } \\
\text { dev. }\end{array}$ & Mean & $\begin{array}{l}\text { St. } \\
\text { dev. }\end{array}$ \\
\hline Ettrick Water $(n=15)$ & 0.99 & 0.01 & 1.89 & 0.08 & 0.999 & 0.001 & 1.92 & 0.04 \\
\hline Afon Ystwyth $(n=15)$ & 0.99 & 0.03 & 1.80 & 0.07 & 0.999 & 0.001 & 1.86 & 0.04 \\
\hline River Lune $(\mathrm{n}=7$ ) & 0.99 & 0.03 & 1.77 & 0.05 & 0.999 & 0.001 & 1.84 & 0.05 \\
\hline Overall (n=37) & 0.99 & 0.02 & 1.83 & 0.09 & 0.999 & 0.001 & 1.88 & 0.05 \\
\hline \multicolumn{9}{|c|}{ (1) These columns are for regression models in which all size fractions have been included. } \\
\hline \multicolumn{9}{|c|}{ (2) These columns are for regression models in which the size fraction containing the largest } \\
\hline (3) Slope coefficient of & gression & model & equival & nt to th & conver & ion fact & derive & from \\
\hline
\end{tabular}


Table 4. Errors associated with the use of empirically- and theoretically-derived conversion factors for image-based area to grid conversions. All values in Psi units.

\begin{tabular}{|c|c|c|c|c|c|c|}
\hline \multirow[t]{2}{*}{ Dataset } & \multicolumn{3}{|c|}{$\begin{array}{l}\text { Empirical conversion } \\
\text { factor, } x^{(1)}\end{array}$} & \multicolumn{3}{|c|}{$\begin{array}{c}\text { Theoretical conversion } \\
\text { factor, } x=2\end{array}$} \\
\hline & $b^{(2)}$ & $E_{m s}^{(3)}$ & $e^{(4)}$ & $b^{(2)}$ & $E_{m s}^{(3)}$ & $e^{(4)}$ \\
\hline Ettrick Water $(x=1.92)$ & -0.005 & 0.001 & 0.032 & -0.062 & 0.007 & 0.052 \\
\hline Afon Ystwyth $(x=1.86)$ & 0.017 & 0.001 & 0.033 & -0.059 & 0.005 & 0.036 \\
\hline River Lune $(x=1.84)$ & 0.009 & 0.001 & 0.024 & -0.047 & 0.004 & 0.037 \\
\hline Overall $(x=1.88)$ & 0.012 & 0.002 & 0.039 & -0.058 & 0.005 & 0.044 \\
\hline \multicolumn{7}{|c|}{ (1) Empirical conversion factor used is the mean for all of the samples at a given site or for th } \\
\hline \multicolumn{7}{|l|}{ overall data set. } \\
\hline \multicolumn{7}{|l|}{${ }^{(2)}$ Procedure bias. } \\
\hline \multicolumn{7}{|l|}{ (3) Mean square error. } \\
\hline
\end{tabular}


Table 5. Regression model parameters for field-based area-to-grid conversions.

\begin{tabular}{|c|c|c|c|c|c|c|c|c|}
\hline \multirow[t]{3}{*}{ Dataset } & \multicolumn{4}{|c|}{ All data ${ }^{(1)}$} & \multicolumn{4}{|c|}{$\begin{array}{l}\text { Excluding largest size } \\
\text { fraction }^{(2)}\end{array}$} \\
\hline & \multicolumn{2}{|c|}{$r^{2}$} & \multicolumn{2}{|c|}{$\begin{array}{l}\text { Conversion } \\
\text { factor, } x^{(3)}\end{array}$} & \multicolumn{2}{|c|}{$r^{2}$} & \multicolumn{2}{|c|}{$\begin{array}{l}\text { Conversion } \\
\text { factor, } x^{(3)}\end{array}$} \\
\hline & Mean & $\begin{array}{l}\text { St. } \\
\text { dev. }\end{array}$ & Mean & $\begin{array}{l}\text { St. } \\
\text { dev. }\end{array}$ & Mean & $\begin{array}{l}\text { St. } \\
\text { dev. }\end{array}$ & Mean & $\begin{array}{l}\text { St. } \\
\text { dev. }\end{array}$ \\
\hline Ain River $(n=10)$ & 0.94 & 0.04 & 2.19 & 0.42 & 0.95 & 0.03 & 2.31 & 0.42 \\
\hline $\begin{array}{l}\text { Fraser River } \\
(n=8)\end{array}$ & 0.81 & 0.20 & 1.89 & 0.29 & 0.95 & 0.03 & 2.08 & 0.31 \\
\hline Overall $(\mathrm{n}=18)$ & 0.88 & 0.14 & 2.06 & 0.39 & 0.95 & 0.02 & 2.21 & 0.38 \\
\hline \multicolumn{9}{|c|}{ (1) These columns are for regression models in which all size fractions have been included } \\
\hline \multicolumn{9}{|c|}{ (2) These columns are for regression models in which the size fraction containing the largest } \\
\hline${ }^{(3)}$ Slope coefficier & of regr & $\sin n$ & dels, ec & ivalent & o the co & versior & factor $\mathrm{d}$ & rived $t$ \\
\hline
\end{tabular}


Table 6. Errors associated with the use of theoretically-derived conversion factors for areato-grid and grid-to-area conversions. All values in Psi units.

\begin{tabular}{|c|c|c|c|c|c|c|}
\hline \multirow[t]{2}{*}{ Dataset } & \multicolumn{3}{|c|}{$\begin{array}{l}\text { Area-to-grid } \\
\text { conversion }^{(1)}\end{array}$} & \multicolumn{3}{|c|}{$\begin{array}{l}\text { Grid-to-area } \\
\text { conversion }^{(2)}\end{array}$} \\
\hline & $b^{(3)}$ & $E_{m s}^{(4)}$ & $e^{(5)}$ & $b^{(3)}$ & $E_{m s}^{(4)}$ & $e^{(5)}$ \\
\hline Ain River $(n=10)$ & -0.054 & 0.091 & 0.298 & -0.198 & 0.086 & 0.216 \\
\hline \multicolumn{7}{|c|}{ (1) Utilizing conversion factor $x=2$ for the theoretical conversion } \\
\hline \multicolumn{7}{|c|}{ (2) Utilizing conversion factor $x=-2$ for the theoretical conversion } \\
\hline \multicolumn{7}{|l|}{ (3) Procedure bias. } \\
\hline \multicolumn{7}{|c|}{ (4) Mean square error. } \\
\hline
\end{tabular}


Table 7. Regression model parameters of number-to-weight conversions.

\begin{tabular}{lcccc}
\hline Datset & \multicolumn{2}{c}{$\mathrm{r}^{2}$} & \multicolumn{2}{c}{ Conversion } \\
& & & factor, $x^{(1)}$ \\
& & & & \\
\cline { 2 - 5 } & Mean & St. & Mean & St. \\
& & dev. & & dev. \\
& & & & \\
\hline Ettrick Water (n=21) & 0.998 & 0.002 & 2.92 & 0.05 \\
Afon Ystwyth (n=18) & & & & \\
River Lune (n=11) & 0.999 & 0.002 & 2.88 & 0.05 \\
& & & & \\
\hline Overall (n=50) & 0.999 & 0.002 & 2.87 & 0.07 \\
& & & & \\
\hline
\end{tabular}

${ }^{(1)}$ Slope coefficient of regression models, equivalent to the conversion factor in equation 1. 
Table 8. Errors associated with the use of empirically- and theoretically-derived conversion factors for conversion between weight- and number-based samples. All values in Psi units.

\begin{tabular}{|c|c|c|c|c|c|c|c|c|c|c|c|c|}
\hline \multirow[t]{3}{*}{ Dataset } & \multicolumn{6}{|c|}{ Weight-to-number conversion } & \multicolumn{6}{|c|}{ Number-to-weight conversion } \\
\hline & \multicolumn{3}{|c|}{$\begin{array}{c}\text { Empirical } \\
\underset{(1)}{\text { conversion factor, } x}\end{array}$} & \multicolumn{3}{|c|}{$\begin{array}{c}\text { Theoretical } \\
\text { conversion factor, } x \\
=-3\end{array}$} & \multicolumn{3}{|c|}{$\begin{array}{c}\text { Empirical } \\
\text { conversion factor, } x\end{array}$} & \multicolumn{3}{|c|}{$\begin{array}{c}\text { Theoretical } \\
\text { conversion factor, } x \\
=3\end{array}$} \\
\hline & $b^{(2)}$ & $E_{m s}^{(3)}$ & $e^{(4)}$ & $b^{(2)}$ & $E_{m s}^{(3)}$ & $e^{(4)}$ & $b^{(2)}$ & $E_{m s}^{(3)}$ & $e^{(4)}$ & $b^{(2)}$ & $E_{m s}^{(3)}$ & $e^{(4)}$ \\
\hline $\begin{array}{l}\text { Ettrick } \\
\text { Water } \\
(x= \\
\pm 2.92)\end{array}$ & $\begin{array}{c}- \\
0.018\end{array}$ & 0.003 & 0.052 & 0.056 & 0.004 & 0.035 & $\begin{array}{c}- \\
0.076\end{array}$ & 0.042 & 0.190 & 0.113 & 0.054 & 0.203 \\
\hline $\begin{array}{l}\text { Afon } \\
\text { Ystwyth } \\
(x= \\
\pm 2.88)\end{array}$ & 0.005 & 0.000 & 0.030 & 0.083 & 0.008 & 0.031 & 0.005 & 0.006 & 0.075 & 0.044 & 0.007 & 0.069 \\
\hline $\begin{array}{l}\text { River } \\
\text { Lune }(x \\
= \\
\pm 2.87)\end{array}$ & 0.021 & 0.004 & 0.060 & 0.105 & 0.014 & 0.055 & 0.009 & 0.004 & 0.062 & 0.059 & 0.007 & 0.059 \\
\hline $\begin{array}{l}\text { Overall } \\
(x= \\
\pm 2.90)\end{array}$ & 0.007 & 0.004 & 0.060 & 0.077 & 0.008 & 0.044 & 0.032 & 0.019 & 0.135 & 0.076 & 0.027 & 0.144 \\
\hline
\end{tabular}

(1) Empirical conversion factor used is the mean for all of the samples at a given site or for the overall data set. They are positive for number-to-weight conversions and negative for weight-to-number conversions.

${ }^{(2)}$ Procedure bias.

${ }^{(3)}$ Mean square error.

${ }^{(4)}$ Irreducible random error. 
Figure 1. Empirical determination of the value of the conversion factor for converting from area-by-number to grid-by-number form for image-based data. (a) The ratio of the percentage of grid-by-number data, $p(G b N)$ to the percentage of the area-bynumber data, $p(A b N)$ in each size fraction, $i$, plotted against the geometric centre of each size fraction $D_{i c}$. Data points are connected by lines for clarity. (b) Gradient of the least-squares regression line for each of the samples, equal to the conversion factor. Bars indicate the $95 \%$ confidence intervals and the dashed line indicates the conversion factor predicted by the Kellerhals and Bray (1971) model (Table 1). (c) Gradient of the least-squares regression line for the samples after removal of the data for the largest size fraction.

Figure 2. For the three field sites (Ettrick Water, Afon Ystwyth, River Lune), covariant plots of the $\Psi_{50}$ and $\Psi_{90}$ (a) derived from image-based data directly in gridby-number $(\mathrm{GbN})$ form and by conversion from area-by-number ( $\mathrm{AbN})$ form using the empirically-derived conversion factor of 1.88; (b) derived directly in grid-bynumber form and by conversion from area-by-number form using the theoreticallyderived conversion factor of 2 . In both parts, the solid line represents the line of equality and the dashed line indicates the bias.

Figure 3. Empirical determination of the value of the conversion factor, for converting from area-by-number to grid-by-number form for field-based data. (a) The ratio of the percentage of grid-by-number data, $p(G b N)$ to the percentage of the areaby-number data $p(A b N)$ in each size fraction, $i$, plotted against the geometric centre of 
each size fraction $D_{i c}$. Data points are connected by lines for clarity. (b) Gradient of the least-squares regression line for each of the samples, equal to the conversion factor. Bars indicate the $95 \%$ confidence intervals and the dashed line indicates the conversion factor predicted by the Kellerhals and Bray (1971) model (Table 1). (c) Gradient of the least-squares regression line for the samples after removal of the data for the largest size fraction.

Figure 4. For the Ain River, covariant plots of the $\Psi_{50}$ and $\Psi_{90}$ (a) derived from fieldbased data directly in grid-by-number ( $\mathrm{GbN}$, pebble count) form and by conversion from area-by-number ( $\mathrm{AbN}$, paint-and-pick) form using the theoretically-derived conversion factor of 2 (b) derived directly in area-by-number form and by conversion from grid-by-number form using the theoretically-derived conversion factor of -2 . In both parts, the solid line represents the line of equality and the dashed line indicates the bias.

Figure 5. Empirical determination of the value of the conversion factor, for converting from area-by-number to area-by-weight form. (a) The ratio of the percentage of area-by-weight, $p(G b N)$ to the percentage of the area-by-number data, $p(A b N)$ in each size fraction, $i$, plotted against the geometric centre of each size fraction $D_{i c}$. Data points are connected by lines for clarity. (b) Gradient of the leastsquares regression line for each of the samples, equal to the conversion factor. Bars indicate the $95 \%$ confidence intervals and the dashed line indicates the conversion factor of 3 predicted by the Kellerhals and Bray (1971) model (Table 1). 
Figure 6. For the three field sites (Ettrick water, Afon Ystwyth, River Lune), covariant plot of the $\Psi_{50}$ and $\Psi_{90}$ (a) derived directly in area-by-number (AbN) form and by conversion from area-by-weight $(\mathrm{AbW})$ form using the empirically-derived conversion factor of -2.90; (b) derived directly in area-by-weight form and by conversion from area-by-number form using the empirically-derived conversion factor of 2.90; (c) in area-by-number form and by conversion from area-by-number form using the theoretically-derived conversion factor of -3 ; (d) derived directly in area-by-weight form and by conversion from area-by-number form using the theoretically-derived conversion factor of 3. In all parts, the solid line represents the line of equality and the dashed line indicates the bias. 


$$
8
$$



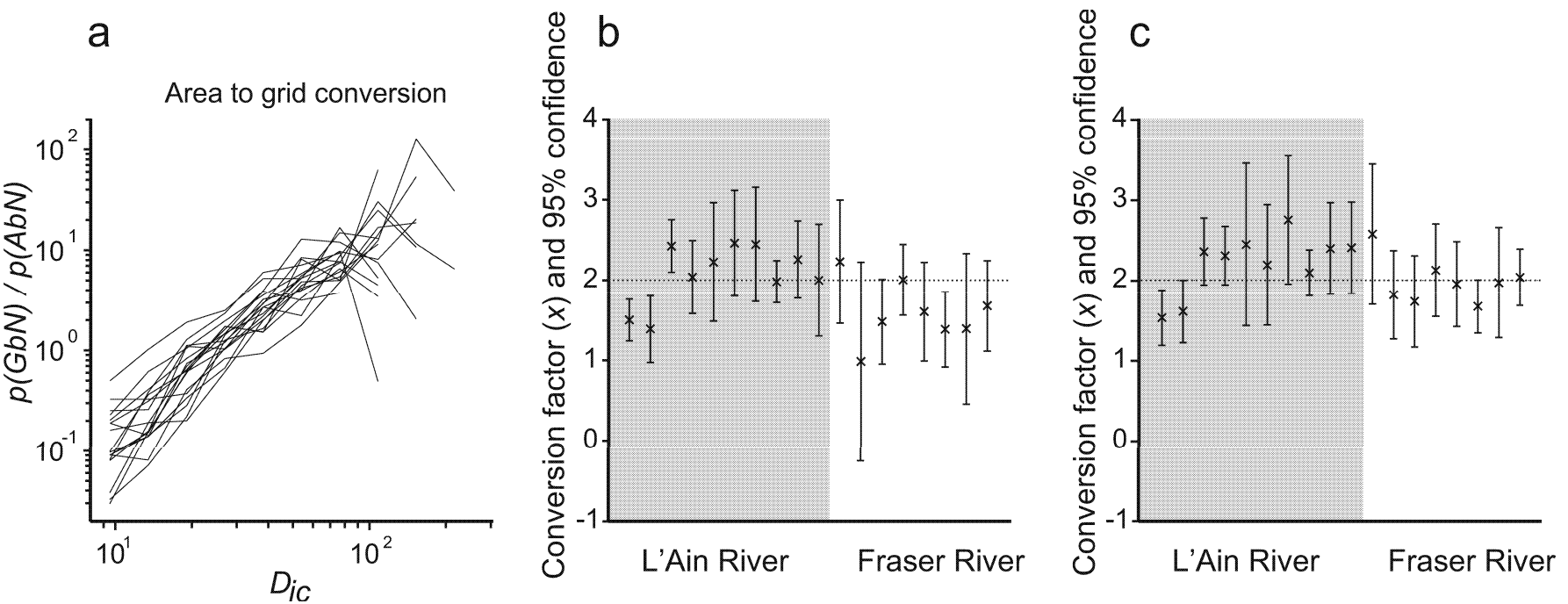
